\title{
STAT3 modulates cigarette smoke-induced inflammation and protease expression
}

\section{Patrick Geraghty ${ }^{1}$, Anne E. Wyman ${ }^{1+}$, Itsaso Garcia-Arcos ${ }^{2}$, Abdoulaye J. Dabo ${ }^{1}$, Sonya Gadhvi ${ }^{1+}$ and $^{\text {Abs }}$ Robert Foronjy ${ }^{1 *}$}

1 Division of Pulmonary and Critical Care Medicine, St. Luke's Roosevelt Health Sciences Center, New York, NY, USA

2 Department of Medicine, Columbia University College of Physicians and Surgeons, New York, NY, USA

\section{Edited by:}

Michael Borchers, University of Cincinnati College of Medicine, USA

\section{Reviewed by:}

Gabriela Krasteva,

Justus-Liebig-University, Germany

Emer P. Reeves, Royal College of

Surgeons in Ireland, Ireland

*Correspondence:

Robert Foronjy, Division of Pulmonary and Critical Care

Medicine, St. Luke's Roosevelt Health Sciences Center, 432 West 58th Street, Room 311, New York, NY 10019, USA

e-mail: robertforonjy@gmail.com

${ }^{\dagger}$ Present address:

Anne E. Wyman, Division of Pulmonary and Critical Care Medicine, University of Maryland, Baltimore, USA;

Sonya Gadhvi, Department of Medicine, Winthrop University Hospital, Mineola, USA
Signal transducer and activator of transcription-3 (STAT3) regulates inflammation, apoptosis, and protease expression, which are critical processes associated with airway injury and lung tissue destruction. However, the precise role of STAT3 in the development of airway diseases such as chronic obstructive pulmonary disease (COPD) has not been established. This study shows that cigarette smoke activates STAT3 in the lungs of mice. Since cigarette smoke activated STAT3 in the lung, we then evaluated how the loss of STAT3 would impact on smoke-mediated lung inflammation, protease expression, and apoptosis. STAT3 ${ }^{+/+}$and STAT3 ${ }^{-/-}$mice were exposed to 8 days of cigarette smoke. Compared to the STAT3 ${ }^{+/+}$mice bronchoalveolar lavage fluid (BALF) cellularity was significantly elevated in the STAT3 ${ }^{-/}$mice both before and after cigarette smoke exposure, with the increase in cells primarily macrophages. In addition, smoke

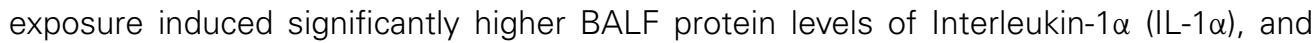
monocyte chemotactic protein-1 (MCP-1) and higher tissue expression of keratinocyte chemoattractant $(\mathrm{KC})$ in the STAT3-/- mice. Lung mRNA expression of MMP-12 was increased in STAT3 ${ }^{-/-}$at baseline. However, the smoke-induced increase in MMP-10 expression seen in the STAT3 ${ }^{+/+}$mice was not observed in the STAT3 ${ }^{-/-}$mice. Moreover, lung protein levels of the anti-inflammatory proteins SOCS3 and IL-10 were markedly lower in the STAT3-/- mice compared to the STAT3 ${ }^{+/+}$mice. Lastly, apoptosis, as determined by caspase $3 / 7$ activity assay, was increased in the STAT3 ${ }^{-1-}$ at baseline to levels comparable to those observed in the smoke-exposed STAT3 ${ }^{+/+}$mice. Together, these results indicate that the smoke-mediated induction of lung STAT3 activity may play a critical role in maintaining normal lung homeostasis and function.

Keywords: inflammation, cytokines, proteases, apoptosis, signaling, lung, COPD

\section{INTRODUCTION}

Chronic obstructive pulmonary disease (COPD) is now the third leading cause of death in the United States (Murphy et al., 2012) and it is projected to become the third leading cause worldwide within the next 20 years (Raherison and Girodet, 2009). In contrast to other diseases, the age-adjusted mortality for COPD has increased over the past 30 years (Miller et al., 2000). Current pharmacological therapies improve lung function and slow disease progression but they have not been shown to impact on COPD mortality (Kim and Criner, 2013). Cigarette smoke is the major etiologic factor associated with this disorder and prolonged exposure to cigarette smoke induces damaging inflammatory, apoptotic, and proteolytic responses in the lung (Macnee, 2007). These biological processes lead to dysfunctional matrix remodeling that cause airway obstruction and lung tissue destruction (Cornwell et al., 2010). A better understanding of the varied signaling processes that mediate the loss of normal airway function is needed to more effectively address the underlying mechanisms of this disease.

Signal transducer and activator of transcription 3 (STAT3) is a transcription factor that mediates IL-6 signaling responses.
Upon binding to the gp130 receptor, IL-6 activates Janus kinases (JAKs), which phosphorylate STAT3 thereby inducing its nuclear translocation and transcriptional activation. In addition to IL6 signaling, STAT3 can be activated by EGFR, PDGFR, and Src kinase. Once activated, STAT3 binds the enhancer element in the promoter region of acute-phase genes, known as the acutephase response element (Gerhartz et al., 1996) and induces the expression of numerous pro-inflammatory genes in the lung (Saleh et al., 2009). STAT3 was recently shown to be required for the development of allergic inflammation in a mouse model of asthma (Simeone-Penney et al., 2007). Indeed, the loss of STAT3 expression within the airway epithelium decreased the expression of Th2 cytokines, lowered airway inflammation and prevented the development of airway hyperreactivity in an asthma model (Simeone-Penney et al., 2007). Conversely, transgenic expression of STAT3 within the alveolar epithelium of mice markedly induced cytokine expression and lung inflammation (Gobburu et al., 1998). Given these findings, STAT3 activation is believed to be a central factor in the induction of airway inflammatory responses. Nevertheless, the role of STAT3 in airway diseases remains to be determined. 
Though STAT3 affects key disease processes, data on the effect of STAT3 in COPD is lacking. Upregulation of STAT3 and induction of genes associated with STAT3 expression have been documented in lung tissue samples from COPD patients (Qu et al., 2009). Since STAT3 expression is increased in COPD, our study examined how cigarette smoke exposure impacted on STAT3 activation in the lungs of mice over the course of 1 year. In addition, we utilized the cigarette smoke exposure model to determine how STAT3 directly affected key biological processes implicated in the development of COPD. To examine this, STAT $3^{+/+}$and STAT3 ${ }^{-/-}$mice were exposed to cigarette smoke in order to assess how the loss of STAT3 impacted on lung inflammation, apoptosis and protease expression.

\section{METHODS \\ ANIMAL MODELS}

Three-month old 129X1-Stat ${ }^{3 t m 1 D e s i} / \mathrm{J} \quad\left(\right.$ STAT3 $\left.^{-/-}\right)$and 129X1/SvJ controls (STAT3 ${ }^{+/+}$) (Jackson Labs, Bar Harbor, $\mathrm{ME})$ were used for these studies. The 129X1-Stat ${ }^{3 t m 1 D e s i} / \mathrm{J}$ mice have a mutant $\beta$ isoform of STAT3 and only express the $\alpha$ isoform. C57Bl/6J mice (Jackson Labs) were used to kinetically examine the effects of cigarette exposure (from 1 day to 1 year of smoke exposure) on STAT3 activity in lung protein. All animal experiments were performed with approval from St. Luke's Roosevelt's Hospital Center's Institutional Animal Care and Use Committee approval.

\section{CIGARETTE SMOKE EXPOSURE PROTOCOL}

In accordance with our previously published protocol (Geraghty et al., 2013), mice were exposed to cigarette smoke from 3R4F research cigarettes (University of Kentucky, Lexington, KY) in a specially designed whole body smoking apparatus (Teague Enterprises, Davis, CA) for $4 \mathrm{~h}$ a day at a total particulate matter concentration of $80 \mathrm{mg} / \mathrm{m}^{3}$. The mice had access to food and water and were able to move about freely during the period of smoke exposure. The mice were euthanized and bronchoalveolar lavage fluid (BALF) and lung tissue was collected $12 \mathrm{~h}$ following the last cigarette smoke exposure.

\section{qPCR}

mRNA was isolated from lung tissue of room air and 8-day smoke exposed STAT3 ${ }^{+/+}$and STAT3 ${ }^{-/-}$mice using Trizol reagent (Life Technologies, Grand Island, NY). cDNA was prepared from this mRNA using Superscript (Life Technologies). Lung expression of Cathepsin S, Cathepsin K, matrix metalloproteinase-3 (MMP-3), MMP-7, MMP-8, MMP-9, MMP-10, MMP-12, MMP13, tumor necrosis factor- $\alpha$ (TNF- $\alpha$ ), IL-1 $\beta$, IL-17, CD68, and KC was assessed by quantitative PCR using Taqman specific probes (Applied Biosystems, Grand Island, NY). Analyzed changes in gene expression in samples were related to another reference sample, usually room air treated STAT3 ${ }^{+/+}$mice where the reference sample is set to 1 .

\section{PROTEASE AND CYTOKINE MEASUREMENTS}

IL-1 $\alpha$, IL-6, IL-10, IL-13, IL-17, IFN- $\gamma$, MCP-1, RANTES (Regulated on Activation, Normal T cell Expressed and Secreted), and TNF- $\alpha$ were measured in BALF using a beads assay on the BioRad Bio-Plex 200 system (BioRad, Hercules, CA).

\section{INTRACELLULAR SIGNALING}

Lung tissue was subfractionated into cytosolic and nuclear fractions using a commercially available protein compartment kit (Millipore, Billerica, MA). Immunoblots were conducted on the cytosolic protein to assess levels of phospho-B cell lymphoma2 protein ( $\mathrm{p}-\mathrm{Bcl}-2), \mathrm{Bcl}-2$, suppressor of cytokine signaling3 (SOCS3) and actin (all antibodies from Cell Signaling, Danvers, MA). The proteins were separated by sodium dodecyl sulfate polyacrylamide gel electrophoresis and then transferred to a nitrocellulose membrane. After blocking for $1 \mathrm{~h}$ with $5 \%$ milk protein (BioRad, Hercules, CA), the membranes were incubated for $1 \mathrm{~h}$ at room temperature with a 1:1000 dilution of primary antibody (p-Bcl2ser70 \#2827, Bcl2 \#2876, SOCS3 \#2932, Actin \#4967) in $2.5 \%$ bovine serum albumin (BSA). After washing, the membranes were then incubated with a 1:4000 dilution of horseradish peroxidase linked secondary antibody (\#7074) in
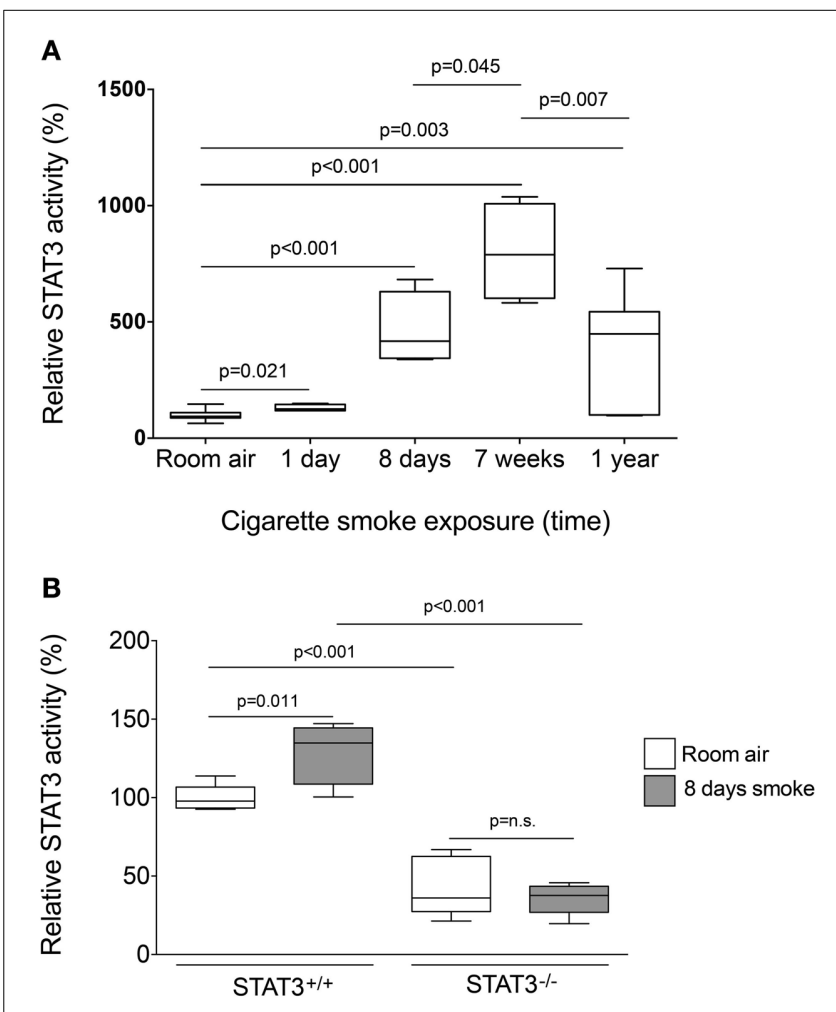

FIGURE 1 | Cigarette smoke exposure induces STAT3 activation in the lungs of exposed mice. (A) Three-month old C57BI/6J mice were exposed to cigarette smoke for 1 day, 8 days, 7 weeks, and 1 year. Nuclear protein fractions were prepared from the lung tissue and STAT3 activity was measured using a specific oligonucleotide-binding assay. (B) Lung nuclear proteins were examined for STAT3 activity from 129X1-Stat ${ }^{3 t m 1 D e s i} / \mathrm{J}$ $\left(\right.$ STAT $^{-/-}$) and $129 \times 1 / \mathrm{SvJ}$ controls $\left(\mathrm{STAT}^{+/+}{ }^{+}\right.$) mice after 8 days of either room air or cigarette smoke exposure. Data are reported as STAT3 activity relative to air-exposed STAT3 ${ }^{+/+}$mice. Plots show range and average \pm S.E.M. $N=10$ in each group. $p$ values shown, comparing both treatments connected by a line. n.s. denotes no significant difference between groups. 
2.5\% BSA for $1 \mathrm{~h}$. After washing, the membranes were incubated with Supersignal West Pico Luminol Enhancer Solution (Thermo Scientific, Rockford, IL) and then imaged on a ChemiDoc XRS Imaging System (BioRad).

\section{STAT3 ACTIVITY}

Lung nuclear protein from the lung tissue homogenates of $\mathrm{C} 57 \mathrm{Bl} / 6 \mathrm{~J}$ mice exposed to 1 day, 8 days, 7 weeks or 1 year of cigarette smoke was used to determine STAT3 activity by conducting an oligonucleotide-binding assay (Active Motif, Carlsbad, CA). Of note, the lung tissue samples had undergone lung lavage prior to measuring STAT3 activity. Results are presented as relative activity compared to controls (\%), which is the reference sample (usually room air treated STAT3 ${ }^{+/+}$mice).

\section{CASPASE 3/7 ACTIVITY ASSAY}

Caspase 3/7 activity was measured in the lung tissue whole lysates of control and smoke-exposed STAT3 ${ }^{+/}$and STAT3 ${ }^{-/-}$ mice using the Caspase-Glo 3/7 Assay System (Promega, Fitchburg, WI). Data is reported as relative luminescence units (RLU). RLU is determined by analysis of signal relative to background, using a Tecan Genios microplate reader.

\section{STATISTICAL ANALYSES}

Data are expressed as means \pm S.E.M. We determined statistical significance by one-way analysis of variance for multiple group analysis using GraphPad Prism Software (GraphPad, La Jolla, CA). Student $t$-tests (two tailed) were used throughout the study. All data sets are represented as range and mean \pm standard error.

\section{RESULTS}

\section{CIGARETTE SMOKE INDUCES STAT3 ACTIVATION IN MOUSE LUNGS}

To determine the STAT3 response to cigarette smoke, STAT3 activity was measured in the nuclear fraction of the lungs of $\mathrm{C} 57 \mathrm{Bl} / 6$ mice subjected to varying periods of smoke exposure. A 30\% increase in STAT3 activation was observed as early as one-day post cigarette smoke exposure (Figure 1). Moreover, 8 days exposure to cigarette smoke further activated STAT3 $\sim 5$ fold. Maximal activation occurred after 7 weeks though increased activity was observed up to 1 year of smoke exposure (Figure 1A). It is conceivable that down regulation of IL-6 receptors or the
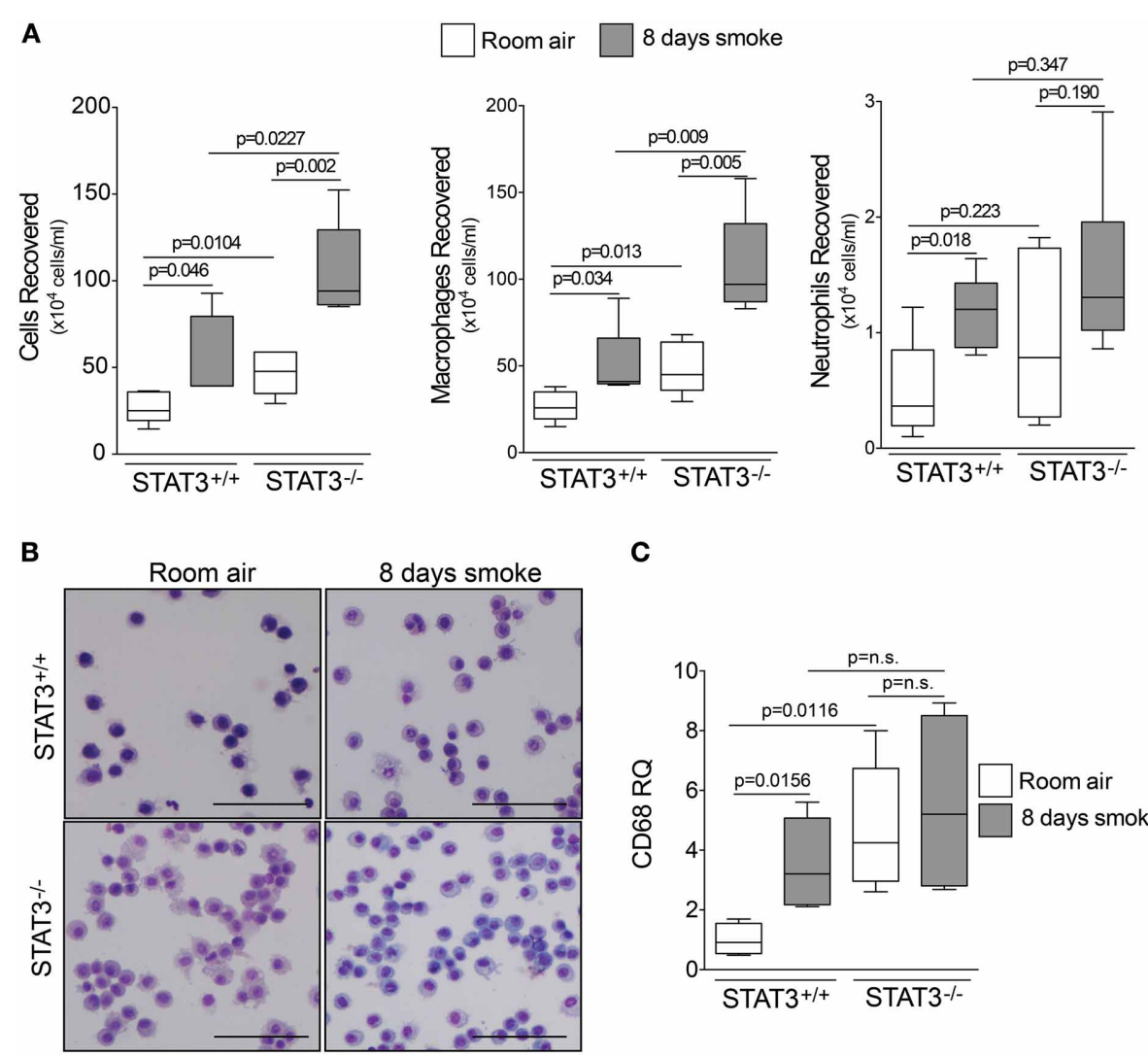

C

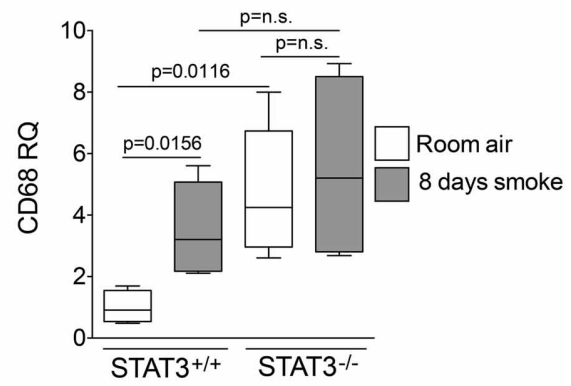

FIGURE 2 | STAT3 expression subdues BALF cellularity. Three-month old STAT3 $^{+/+}$and STAT3 ${ }^{-/-}$mice were exposed to room air (white bars) or cigarette smoke (black bars) for $4 \mathrm{~h}$ daily for 8 days. The mice were euthanized $12 \mathrm{~h}$ post the last smoke exposure and (A) BALF cellularity was measured by bright field microscopy. BALF macrophages and neutrophils were determined by quick diff staining. (B) A typical representative staining is shown here (Scale bar $=20 \mu \mathrm{M}$ ). (C) qPCR for macrophage marker CD68 also demonstrates higher levels of macrophages within the lung tissue. Data are reported as BALF cells ( $x$ 10,000). Plots show range and average \pm S.E.M. $N=10$ in each group. $p$ values shown, comparing both treatments connected by a line. n.s. denotes no significant difference between groups. 
induction of protein inhibitor of activated STAT3 (PIAS3) may have diminished the smoke-mediated induction of STAT3 at the 1-year time point. However, this will need to be explored in future studies. Together, these results show that cigarette smoke causes a rapid and persistent activation of STAT3 in the lung.

\section{INCREASED INFLAMMATORY CELLS IN THE AIRWAYS OF STAT3-/- MICE}

Since cigarette smoke potently activated STAT3 in the lungs of mice, we aimed to determine how the loss of STAT3 would impact on smoke-mediated inflammatory responses. To address this question, we exposed 129X1-Stat ${ }^{3 t m 1 D e s i} / \mathrm{J}^{\left(\mathrm{STAT}^{-/-}\right)}$and $129 \mathrm{X} 1 / \mathrm{SvJ}\left(\mathrm{STAT}^{+/+}\right)$mice to 8 days of cigarette smoke exposure. Cigarette smoke increased STAT3 activity levels with the lung of the STAT3 ${ }^{+/+}$after 8 days of smoke exposure (Figure 1B). Cigarette smoke significantly increased BALF cellularity in the lungs of the STAT3 ${ }^{+/+}$mice $\left(26.8 \pm 3.7 \times 10^{4}\right.$ vs. $53.9 \pm 13.3 \times 10^{4}$ cells for room air and smoke exposed, respectively; $p<0.05$ ) (Figure 2A). In comparison, the STAT3 ${ }^{-/-}$mice under room air conditions had significantly higher lung BALF cellularity than STAT3 ${ }^{+/+}$mice $\left(26.8 \pm 3.7 \times 10^{4}\right.$ vs. $48.2 \pm 5.8 \times$ $10^{4}$ cells for STAT3 ${ }^{+/+}$and STAT3 ${ }^{-/-}$, respectively; $\left.p<0.05\right)$. In fact, the BALF cellularity of room air exposed STAT3-/mice was comparable to that of $\mathrm{STAT}^{+/+}$mice that had been exposed to cigarette smoke for 8 days (Figure 2A). The increase in BALF cells was primarily macrophages (Figure 2B). Consistent with the increase in BALF cells that was measured in the BALF, we found significantly higher expression of the macrophage marker CD68 in the STAT3 ${ }^{-/}$mice under room air conditions compared to the room air exposed STAT3 ${ }^{+/+}$ mice (Figure 2C). Cigarette smoke exposure caused a two-fold increase in BALF cellularity in the STAT3 ${ }^{-/}$mice compared to room air exposed STAT3 ${ }^{-/}$mice (Figure 2A). This smokemediated increase was proportional to that experienced by the smoke-exposed STAT3 ${ }^{+/+}$mice though the STAT3 ${ }^{+/+}$had significantly lower levels of inflammatory cells post exposure compared to the STAT3 ${ }^{-/-}$mice. Together, these findings show that the lack of STAT3 activation alters immune cell infiltration in the lung.

\section{STAT3 EXPRESSION IMPACTS ON LUNG CYTOKINE AND PROTEASE INDUCTION}

Cigarette smoke induces the expression of pro inflammatory cytokines and destructive proteases in the lung (Foronjy and D'Armiento, 2001; Wright et al., 2002). For this reason, we evaluated how the loss of STAT3 altered lung cytokine and protease expression in smoke-exposed mice. Under room air exposure conditions, TNF- $\alpha$ BALF protein levels were significantly higher in STAT3 ${ }^{-/-}$mice than in STAT3 ${ }^{+/+}$mice $(\sim 2$-fold, $p<0.05)$ (Figure 3). In response to cigarette smoke, IL-1 $\alpha$ BALF protein levels decreased in the STAT3 ${ }^{+/+}$mice $(p<0.05)$, but trended higher in the STAT3 ${ }^{-/-}$mice (Figure 3 ). In contrast, cigarette smoke increased MCP-1 BALF protein levels in the STAT3-/mice, but not in the STAT3 ${ }^{+/+}$mice (Figure 3 ). STAT3 had no effect on the smoke-mediated increase in IFN- $\gamma$ and IL17 BALF protein expression and neither cigarette smoke nor

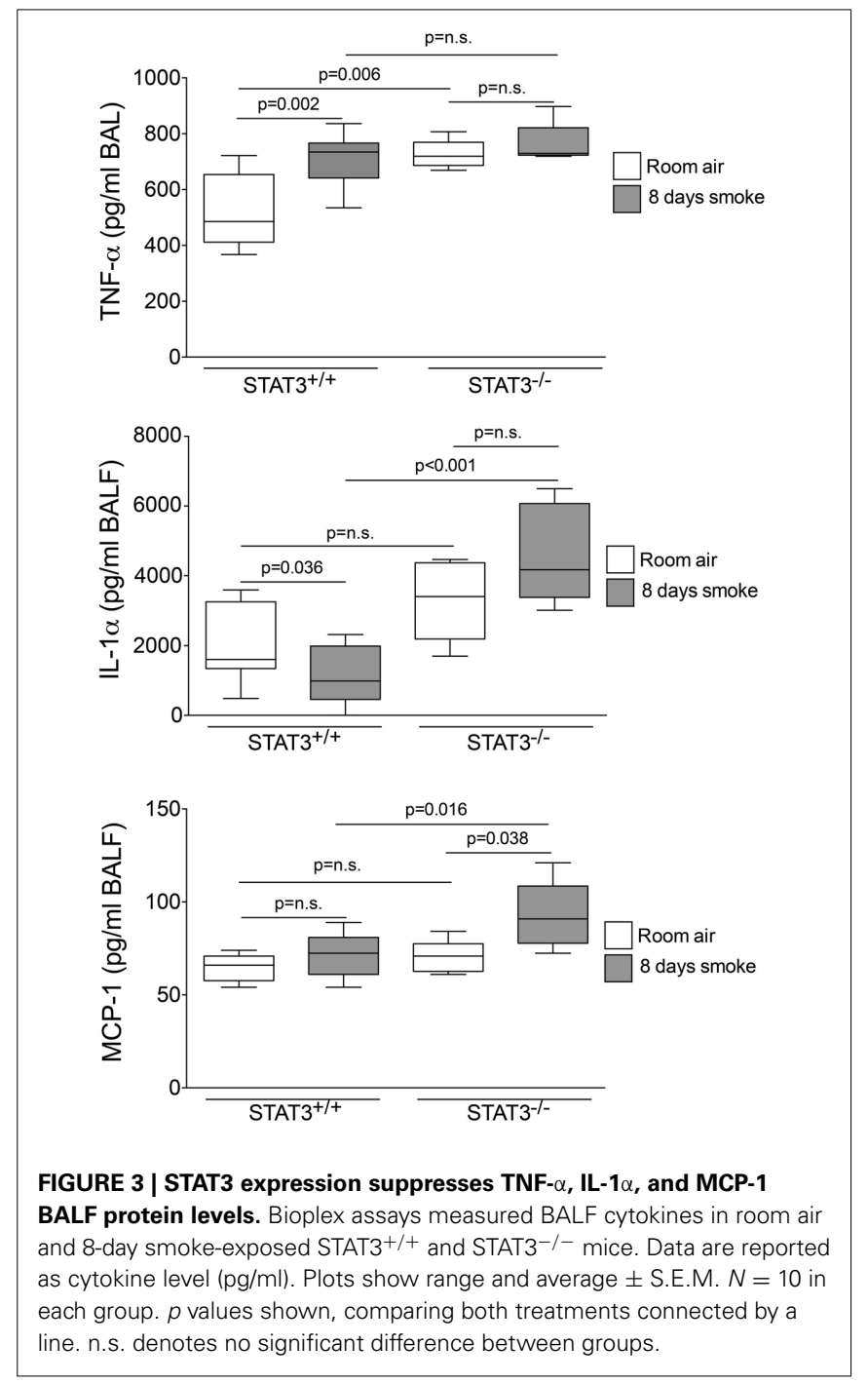

STAT3 expression altered RANTES or IL-6 BALF protein levels (Figure 4). Of note, IL-10 has potent anti-inflammatory effects in the lung (Mays et al., 2013) and BALF protein levels of the anti-inflammatory cytokine IL-10 were significantly lower in the STAT3 $^{-/}$mice under room air conditions (Figure 4). We next conducted quantitative PCR analyses to determine how STAT3 impacted on cytokine and protease expression within the lung tissue of the mice. We found that $\mathrm{KC}$ was regulated both by cigarette smoke exposure and STAT3 expression. Compared to STAT3 $^{+/+}$mice, the STAT3 ${ }^{-/-}$mice had a $\sim 3$-fold increase in lung $\mathrm{KC}$ expression under room air conditions (Figure 5). Furthermore, cigarette smoke induced a 2-fold increase in $\mathrm{KC}$ expression in STAT $3^{+/+}$mice $(p<0.05)$, but a $\sim 15$-fold increase in STAT3 $^{-/-}$mice $(p<0.05$ vs. room air and vs. smoked wild type; Figure 5). In terms of proteases, cigarette smoke induced a $\sim 10$-fold increase in MMP-10 lung mRNA expression $(p<0.01)$ in the STAT3 ${ }^{+/+}$mice but not in the smokeexposed STAT3 ${ }^{-/-}$mice (Figure 5). Importantly, lung MMP-12 mRNA expression was upregulated $\sim 8$-fold in the STAT3 ${ }^{-/-}$ mice under room air conditions $(p<0.02)$. However, MMP-12 


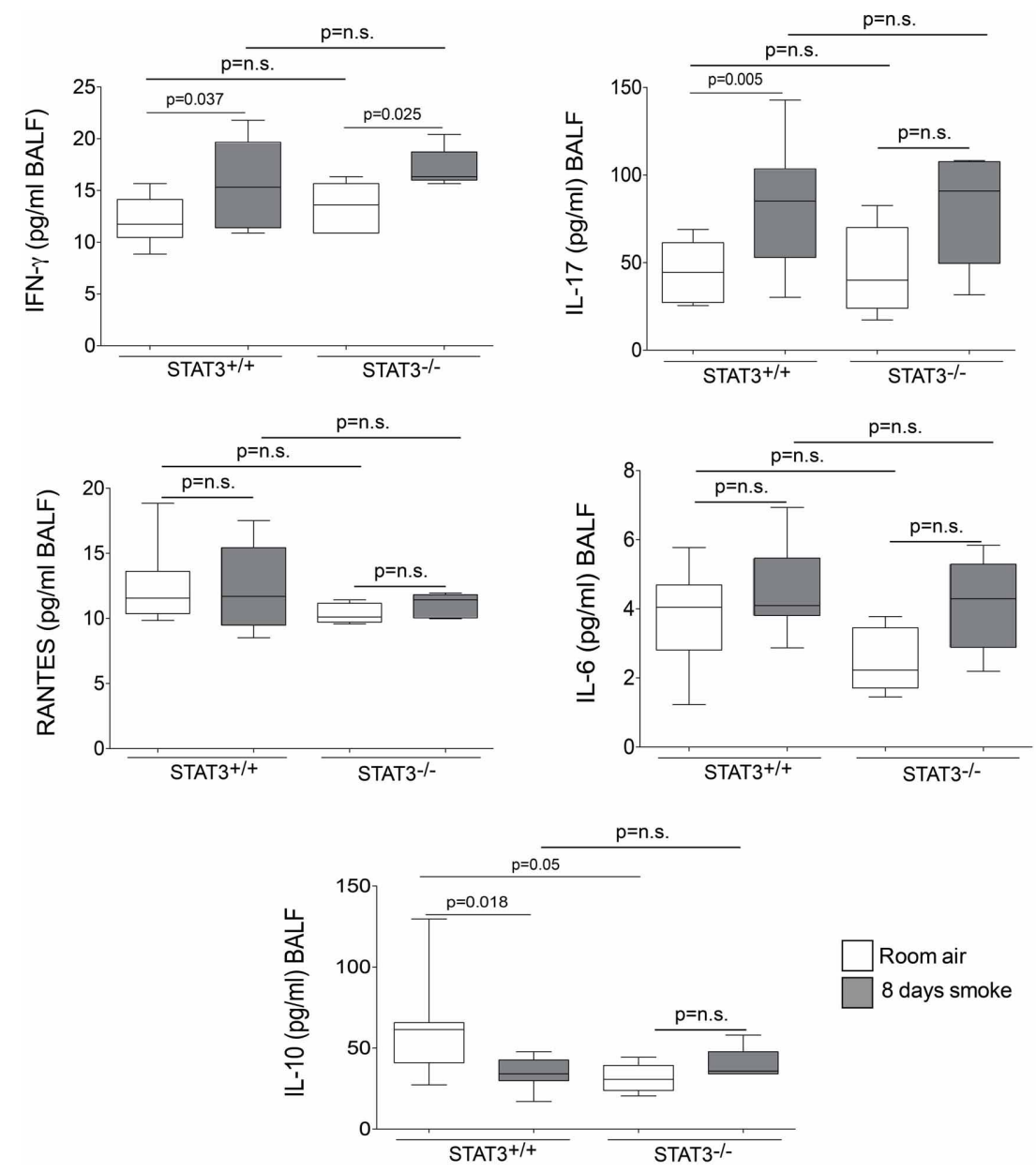

FIGURE 4 | STAT3 expression impacts on IL-10 BALF protein levels. Bioplex assays measured BALF cytokines (IFN- $\gamma$, IL-17, RANTES, IL-6, and IL-10) in room air and 8-day smoke-exposed STAT3 ${ }^{+/+}$and $\mathrm{STAT}^{-/-}$mice.
Data are reported as cytokine level (pg/ml). Plots show range and average \pm S.E.M. $N=10$ in each group. $p$ values shown, comparing both treatments connected by a line. n.s. denotes no significant difference between groups. expression was comparable in STAT3 ${ }^{+/+}$and STAT3 ${ }^{-/-}$mice following cigarette smoke exposure. Similarly, TNF- $\alpha$, IL-1 $\beta$, and MCP-1 lung tissue expression were comparable in the STAT $^{+/+}$and STAT3 ${ }^{-/-}$mice under smoke exposure conditions (Figure 6).

\section{LOSS OF STAT3 IMPACTS ON SOCS3 PROTEIN LEVELS IN THE LUNG}

Suppressor of cytokine synthesis 3 (SOCS3) counters inflammation by blocking JAK and their associated receptors to limit the duration and intensity of cytokine signaling (Babon and Nicola, 2012). Compared to STAT $3^{+/+}$mice, both SOCS3 protein expression was markedly lower in the STAT $3^{-/-}$mice (Figure 7 ). Thus, the loss of STAT3 expression may enhance lung inflammation by diminishing the anti-inflammatory responses mediated by SOCS3.

\section{CASPASE 3/7 ACTIVITY IS INCREASED IN THE LUNGS OF THE STAT3-/- MICE}

Apoptosis is a critical process in the development of emphysema (Tuder et al., 2003) and STAT3 regulates apoptotic responses in vivo (Chapman et al., 2000; Abell et al., 2005). Thus, we sought to determine how the loss of STAT3 expression impacted on apoptotic responses in the lungs of smoke-exposed mice. We measured caspase $3 / 7$ activity, an important marker of apoptosis (Albee et al., 2007), in the lungs of room air and 8-day smoke-exposed STAT3 ${ }^{+/+}$and STAT3 ${ }^{-/-}$mice. Cigarette smoke induced a $\sim 20$ fold increase in caspase $3 / 7$ activity in the smokeexposed STAT3 ${ }^{+/+}$mice $(p<0.001)$ (Figure 8). Compared to the STAT $3^{+/+}$mice, the STAT3 ${ }^{-/-}$had a $\sim 10$ fold increase in caspase $3 / 7$ activity at baseline $(p<0.01)$. However, the heightened activity did not increase further increase with cigarette smoke exposure in STAT3 ${ }^{-/-}$mice (Figure 8). STAT3 can regulate apoptosis by inducing the expression of the apoptotic inhibitor Bcl-2 (Gao and Ward, 2007). Given this, immunoblots for $\mathrm{p}-\mathrm{Bcl}-2$ and total $\mathrm{Bcl}-2$ were conducted on lung tissue lysates from control and 8-day smoke-exposed STAT3 ${ }^{+/+}$and STAT3 ${ }^{-/}$mice. The expression of both $\mathrm{p}-\mathrm{Bcl}-2$ and total Bcl-2 showed a trend toward an increase in STAT3 ${ }^{+/+}$mice exposed to smoke, while the trend was the opposite in the STAT3 ${ }^{-/-}$mice (Figure 9). However, the difference in p-Bcl-2 levels in the smoke 
exposed STAT3 ${ }^{+/+}$and $\mathrm{STAT}^{-/-}$mice did not reach statistical significance.

\section{DISCUSSION}

The role of STAT3 in inflammation is not clearly defined, with evidence supporting STAT3 activation having pro-inflammatory and anti-inflammatory roles (El Kasmi et al., 2006; Ruwanpura et al., 2012). These varied effects may be due to disease- and

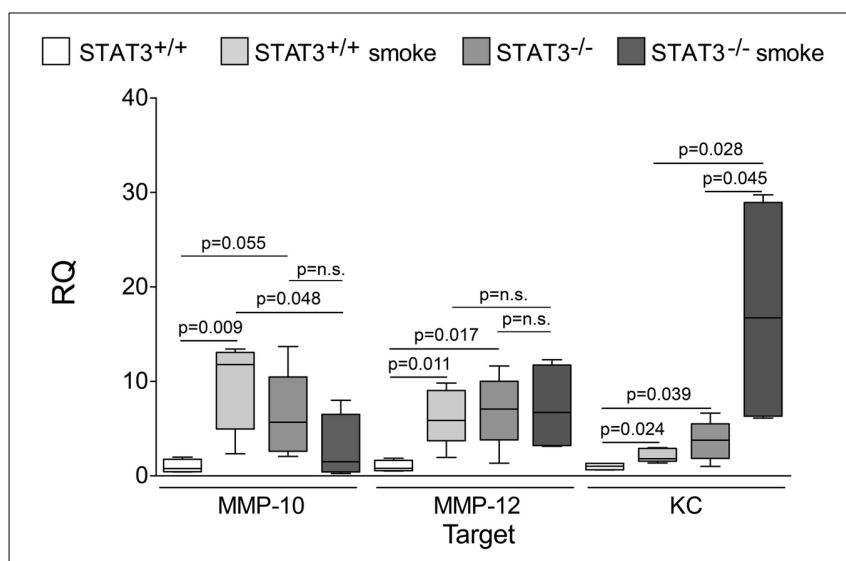

FIGURE 5 | Loss of lung STAT3 activity enhances gene expression of MMP-10 and MMP-12. Quantitative PCR for mouse KC, MMP-10, and MMP-12 was conducted on mRNA isolated from the lung tissue of room air and 8-day smoke exposed STAT3 ${ }^{+/+}$and STAT3 ${ }^{-/-}$mice using specific Taqman probes. Data are reported as relative expression (RQ) to $\mathrm{STAT}^{+/+}$ in room air conditions. Plots show range and average \pm S.E.M. $N=10$ in each group. $p$ values shown, comparing both treatments connected by a line. n.s. denotes no significant difference between groups. cell-specific mechanisms that determine the ultimate effect that STAT3 exerts in a biological system. The expression of STAT3 and its downstream-related genes is significantly increased in the lung tissue of COPD patients (Qu et al., 2009). This is significant as STAT3 is known to regulate inflammation, protease expression, and apoptosis ( $\mathrm{Li}$ et al., 2011; Camporeale and Poli, 2012; Du et al., 2012), which are key biological processes in the pathogenesis of COPD (Chung and Adcock, 2008). For this reason, we sought to determine how the loss of STAT3 would impact on these important disease parameters in the cigarette smoke exposure model. This work shows for the first time that STAT3 $^{-/-}$mice have enhanced inflammatory, proteolytic and apoptotic responses in response to cigarette smoke. Furthermore, the loss of STAT3 expression was associated with deficient antiinflammatory responses in these mice. STAT3 has been viewed as a potential therapeutic target for the treatment of COPD (Gao and Ward, 2007). However, these findings suggest that STAT3 may have protective functions in the lung and inhibiting it could exacerbate the underlying mechanisms involved in cigarette smoke-induced lung diseases.

One of the most remarkable findings in the $\mathrm{STAT}^{-/-}$mice was the increased numbers of BALF cells, mostly macrophages, under room air or smoke exposure conditions. Macrophages are critical in COPD as these cells release proteases that induce dysfunctional airway remodeling (Shapiro et al., 1991; Shapiro, 1999, 2003). This enhanced macrophage response may have been due to the increased MCP-1 expression that was detected in the STAT3 ${ }^{-/-}$mice. MCP-1 is upregulated in COPD patients (Bracke et al., 2007) and induces mucin production and lung inflammation (de Boer et al., 2000; Monzon et al., 2011) characterized by the influx of macrophages (Hautamaki et al., 1997). It is somewhat surprising that the absence of STAT3
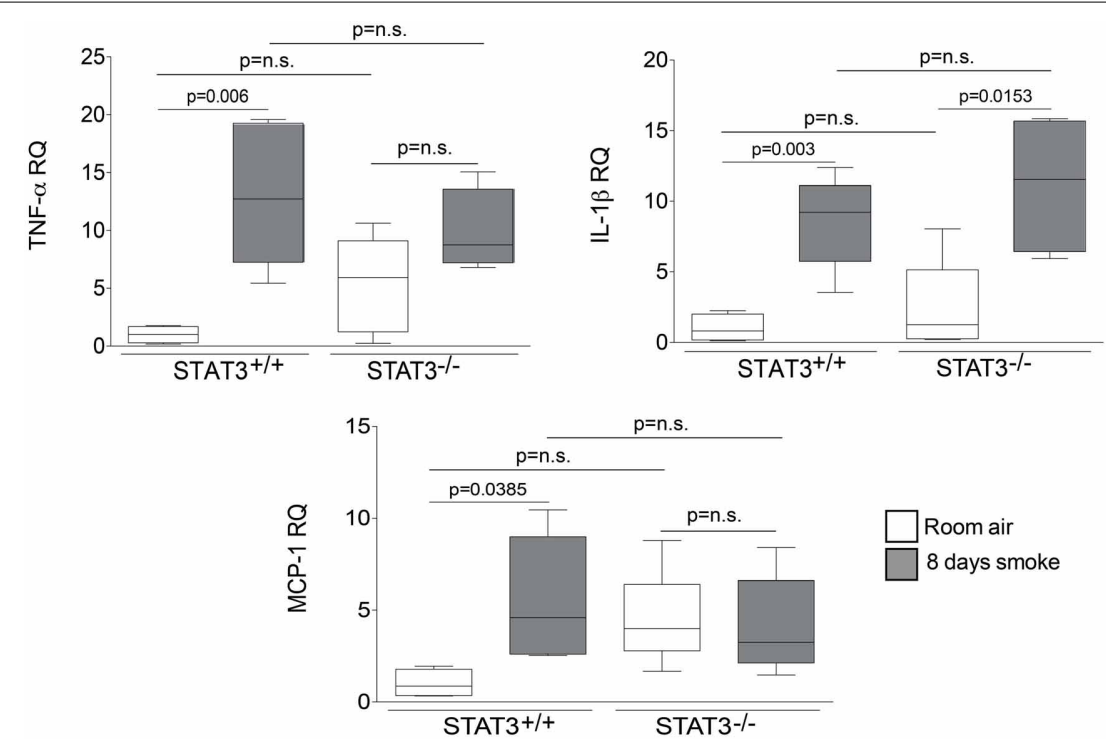

FIGURE 6 | STAT3 does not alter lung expression of TNF- $\alpha$, IL-1 $\beta$ or MCP-1. Quantitative PCR for mouse TNF- $\alpha, I L-1 \beta$ or MCP-1 was conducted on mRNA isolated from the lung tissue of room air and 8-day smoke exposed $\mathrm{STAT}^{+/+}$and STAT3 ${ }^{-/-}$mice using specific Taqman probes. Data are reported as relative expression $(\mathrm{RQ})$ to $\mathrm{STAT}^{+/+}$in room air conditions. Plots show range and average \pm S.E.M. $N=10$ in each group. $p$ values shown, comparing both treatments connected by a line. n.s. denotes no significant difference between groups. 

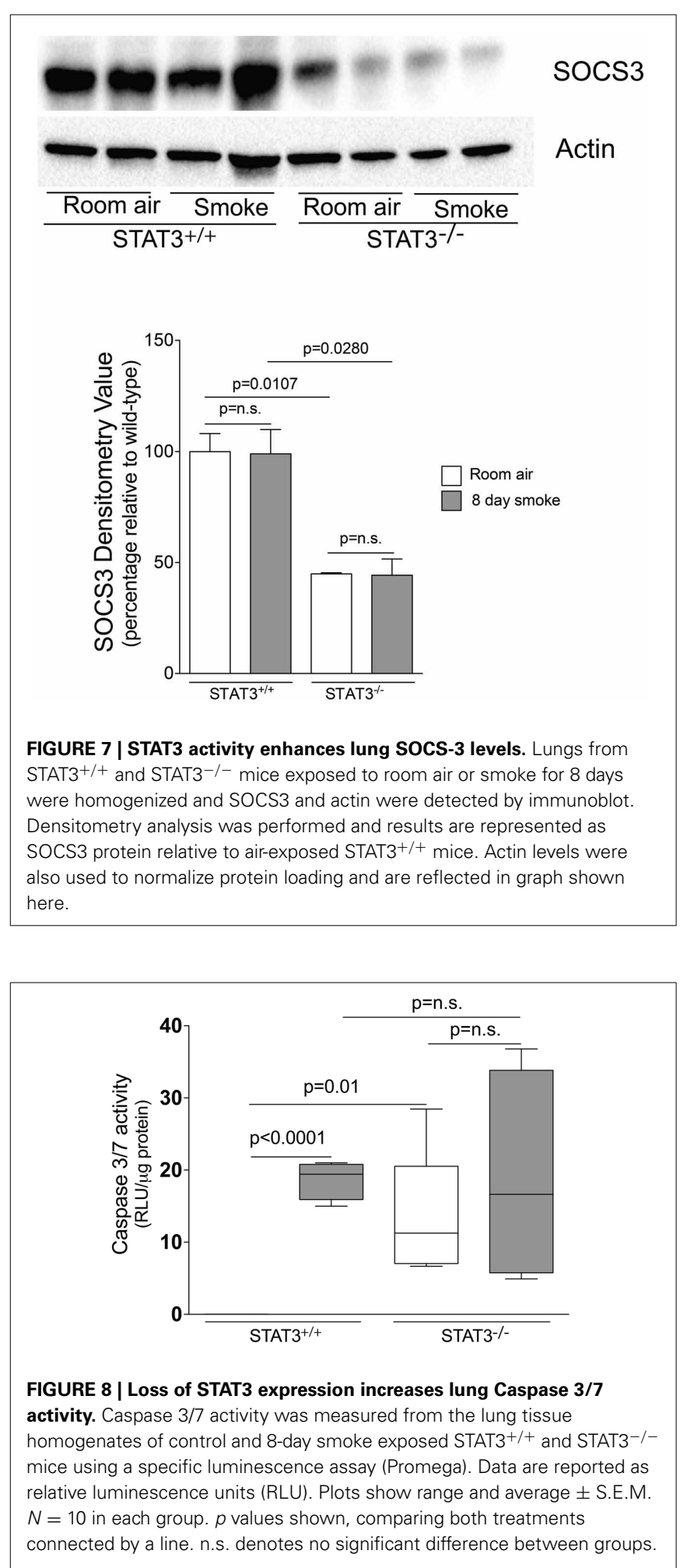

increased MCP-1 levels as several studies demonstrated that MCP-1 expression is positively regulated by STAT3 (Burysek et al., 2002; Chatterjee et al., 2009; Zhou et al., 2012). However, the effect of STAT3 is likely influenced by the cell type and physiologic context. Indeed, the loss of STAT3 expression in

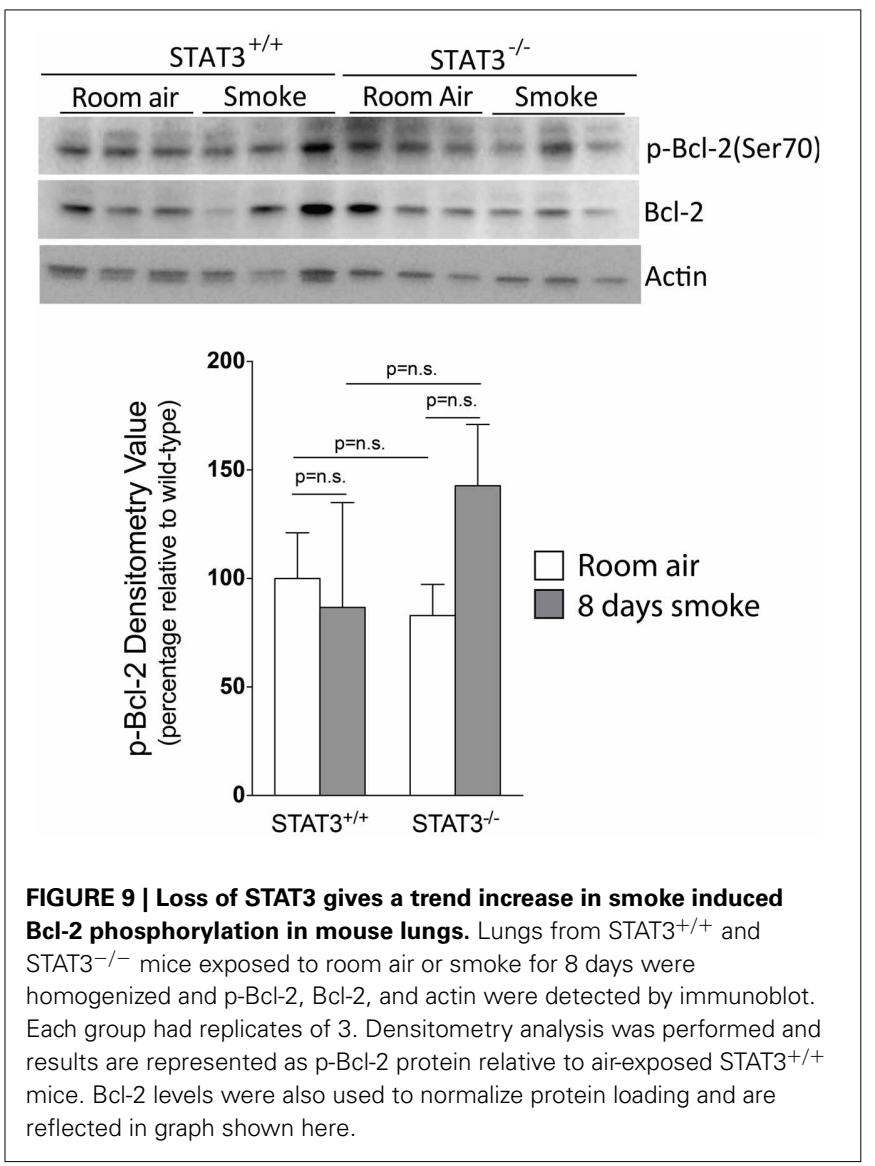

macrophages enhanced inflammatory responses and increased MCP-1 expression in thioglycollate-challenged mice (Matsukawa et al., 2005).

In addition to the changes in MCP-1 expression, baseline TNF- $\alpha$ levels were significantly increased in the STAT3 ${ }^{-/-}$mice. TNF- $\alpha$, which is expressed by macrophages and other resident lung cells, induces intracellular signaling events that promote the development of emphysema (Riches et al., 1996; Churg et al., 2004). Thus, our findings indicate that STAT3 expression can impact on the disease by countering TNF- $\alpha$ expression in the lung. Of note, STAT3 regulated BALF TNF- $\alpha$ protein levels but not lung tissue TNF- $\alpha$ expression. This may indicate that STAT3 has a greater role on macrophage TNF- $\alpha$ expression than it does on lung tissue TNF- $\alpha$ expression. In support of this, prior studies have shown that the induction of SOCS3 by STAT3 counters TNF- $\alpha$ expression in macrophages (Berlato et al., 2002; Williams et al., 2004). However, further studies will be needed to definitively evaluate the effect of STAT3 within specific cell types in this model.

In addition to TNF- $\alpha$, STAT3 also deterred the smokemediated induction of IL- $1 \alpha$ in mice. This is significant as IL- $1 \alpha$ drives the influx of neutrophils in the lungs of COPD patients (Botelho et al., 2011) and neutralizing IL-1 $\alpha$ attenuates cigarette smoke-induced inflammation in mice (Pauwels et al., 2011). The enhanced inflammatory response in the STAT3 ${ }^{-/-}$mice was associated with increased MMP-12 expression. The fact that 
STAT3 negatively regulated MMP-12 is significant as this protease is upregulated in COPD patients (Demedts et al., 2006; Ilumets et al., 2007) and plays a critical role in smoke-induced emphysema in mice (Hautamaki et al., 1997). While the loss of STAT3 increased MMP-12 expression, STAT3-/- mice had significantly lower lung expression of MMP-10 following cigarette smoke exposure. This is important as MMP-10 was found to decrease inflammation in a mouse model of experimental colitis (Koller et al., 2012). Thus, it is conceivable that the loss of STAT3 expression can enhance lung inflammation by diminishing MMP-10 expression in the lung.

The loss of STAT3 expression greatly impaired innate antiinflammatory responses in the lung. SOCS3 expression is positively regulated by STAT3 and, once activated, SOCS3 binds gp130 and inhibits Janus activated kinase (JAK) activity. Through this mechanism, SOCS3 then modulates immune responses by down regulating IL-1 and IL-6 signaling (Croker et al., 2003; Frobose et al., 2006) and deterring MAPK activation (Puhr et al., 2010). Thus, SOCS blocks key factors in the pathogenesis of COPD (Mercer et al., 2004; Botelho et al., 2011). The loss of SOCS3 expression in macrophages causes a polarization into an M1 or pro inflammatory phenotype (Qin et al., 2012a) and can enhance cell death and apoptosis (Ruan et al., 2010; Qin et al., 2012b). This may explain the increased macrophage levels and heightened apoptotic responses observed in our study. Aside from SOCS3, basal levels of the anti-inflammatory cytokine IL-10 were significantly lower in the STAT3 ${ }^{-/-}$mice. IL-10 is positively regulated by STAT3 (Benkhart et al., 2000) and IL-10 deficiency renders the lung more sensitive to pro inflammatory stimuli (Penttila et al., 2008). Thus, we assert that the loss of STAT3 expression enhanced susceptibility to smoke-induced inflammation by decreasing IL10 levels in the lung. Lastly, the STAT3 ${ }^{-/-}$mice did not increase MMP-10 expression in response to cigarette smoke exposure. While most MMPs are believed to promote lung inflammation, MMP-10 exerts anti-inflammatory effects and promotes repair responses following tissue injury (Rodriguez et al., 2008; Koller et al., 2012). Together, these results show that the loss of STAT3 expression causes deficient anti-inflammatory and repair processes in mice.

\section{REFERENCES}

Abell, K., Bilancio, A., Clarkson, R. W., Tiffen, P. G., Altaparmakov, A. I., Burdon, T. G., et al. (2005). Stat3-induced apoptosis requires a molecular switch in $\mathrm{PI}(3) \mathrm{K}$ subunit composition. Nat. Cell Biol. 7, 392-398. doi: 10.1038/ ncb 1242

Albee, L., Shi, B., and Perlman, H. (2007). Aspartic protease and caspase $3 / 7$ activation are central for macrophage apoptosis following infection with Escherichia coli. J. Leukoc. Biol. 81, 229-237. doi: 10.1189/jlb.0506358

Babon, J. J., and Nicola, N. A. (2012). The biology and mechanism of action of suppressor of cytokine signaling 3. Growth Factors 30,
207-219. doi: 10.3109/08977194. 2012.687375

Benkhart, E. M., Siedlar, M., Wedel, A., Werner, T., and Ziegler-Heitbrock, H. W. (2000). Role of Stat3 in lipopolysaccharide-induced IL-10 gene expression. J. Immunol. 165, 1612-1617.

Berlato, C., Cassatella, M. A., Kinjyo, I., Gatto, L., Yoshimura, A., and Bazzoni, F. (2002). Involvement of suppressor of cytokine signaling-3 as a mediator of the inhibitory effects of IL-10 on lipopolysaccharide-induced macrophage activation. J. Immunol. 168, 6404-6411.

Botelho, F. M., Bauer, C. M., Finch, D., Nikota, J. K., Zavitz, C. C., Kelly, A., et al. (2011). IL-1alpha/IL-1R1

There are several study limitations that merit discussion. For one, constitutive STAT3 ${ }^{-/}$mice were utilized. STAT3 plays an important role in myeloid cell maturation and differentiation (Smithgall et al., 2000). Thus, the lack of STAT3 activation may have altered the development of the immune system to render the STAT3 ${ }^{-/}$mice more responsive to cigarette smoke exposure. Moreover, since a whole body knockout was used the study cannot address the effect of STAT3 loss specifically in the lung. Lastly, though the loss of STAT3 exacerbated inflammation, protease expression and apoptosis, it is uncertain whether these effects would have increased lung tissue destruction in the smokeexposed mice. Long-term smoke exposure studies and complete morphological analyses are needed to address this question.

In summary, our findings show that STAT3 is activated by cigarette smoke exposure, which may regulate key inflammatory, proteolytic and apoptotic responses in the lung. STAT3 mediates these effects at least in part by modulating anti-inflammatory responses such as SOCS3 and IL-10 expression in the lung. Future studies are needed to address the role of STAT3 in the disease to determine whether targeting STAT3 activity could be used as an approach to counter the injurious effects of cigarette smoke exposure in the lung.

\section{AUTHOR CONTRIBUTIONS}

Patrick Geraghty, Anya Wyman, Itsaso Garcia-Arcos, Abdoulaye J. Dabo and Sonya Gadhvi conducted the animal studies and interpreted experimental results. Patrick Geraghty and Itsaso Garcia-Arcos wrote the paper. Robert Foronjy led the project, interpreted the data and wrote the paper.

\section{ACKNOWLEDGMENTS}

The authors would like to thank the James P. Mara Center for Lung Diseases for their generous support. This work was supported by grants made available to Patrick Geraghty [Flight Attendant Medical Research Institute (YCSA 113380)] and Robert Foronjy (Flight Attendant Medical Research Institute (YCSA 24039) (CIA 074047) and (US National Institutes of Health 1R01HL098528-05).

expression in chronic obstructive pulmonary disease and mechanistic relevance to smoke-induced neutrophilia in mice. PLOS ONE 6:e28457. doi: 10.1371/journal. pone. 0028457

Bracke, K. R., Demedts, I. K., Joos, G. F., and Brusselle, G. G. (2007). CC-chemokine receptors in chronic obstructive pulmonary disease. Inflamm. Allergy Drug Targets 6, 75-79. doi: 10.2174/187152807780832292

Burysek, L., Syrovets, T., and Simmet, T. (2002). The serine protease plasmin triggers expression of MCP-1 and CD40 in human primary monocytes via activation of p38 MAPK and janus kinase (JAK)/STAT signaling pathways.
J. Biol. Chem. 277, 33509-33517. doi: 10.1074/jbc.M201941200

Camporeale, A., and Poli, V. (2012). IL-6, IL-17 and STAT3: a holy trinity in auto-immunity? Front. Biosci. 17, 2306-2326. doi: 10.2741/ 4054

Chapman, R. S., Lourenco, P., Tonner, E., Flint, D., Selbert, S., Takeda, K., et al. (2000). The role of Stat 3 in apoptosis and mammary gland involution. Conditional deletion of Stat3. Adv. Exp. Med. Biol. 480, 129-138. doi: 10.1007/0-30646832-8_16

Chatterjee, P. K., Al-Abed, Y., Sherry, B., and Metz, C. N. (2009). Cholinergic agonists regulate JAK2/STAT3 signaling to suppress endothelial cell activation. Am. J. Physiol. Cell 
Physiol. 297, C1294-C1306. doi: 10.1152/ajpcell.00160.2009

Chung, K. F., and Adcock, I. M. (2008). Multifaceted mechanisms in COPD: inflammation, immunity, and tissue repair and destruction. Eur. Respir. J. 31, 1334-1356. doi: 10.1183/09031936.00018908

Churg, A., Wang, R. D., Tai, H., Wang, X., Xie, C., and Wright, J. L. (2004). Tumor necrosis factoralpha drives $70 \%$ of cigarette smoke-induced emphysema in the mouse. Am. J. Respir. Crit. Care Med. 170, 492-498. doi: 10.1164/rccm.200404-511OC

Cornwell, W. D., Kim, V., Song, C., and Rogers, T. J. (2010). Pathogenesis of inflammation and repair in advanced COPD. Semin. Respir. Crit. Care Med. 31, 257-266. doi: 10.1055/s-0030-1254066

Croker, B. A., Krebs, D. L., Zhang, J. G., Wormald, S., Willson, T. A., Stanley, E. G., et al. (2003). SOCS3 negatively regulates IL-6 signaling in vivo. Nat. Immunol. 4, 540-545. doi: $10.1038 / \mathrm{ni} 931$

de Boer, W. I., Sont, J. K., van Schadewijk, A., Stolk, J., van Krieken, J. H., and Hiemstra, P. S. (2000). Monocyte chemoattractant protein 1, interleukin 8 , and chronic airways inflammation in COPD. J. Pathol. 190, 619-626. doi: 10.1002/(SICI)10969896(200004)190:5<619::AIDPATH555>3.0.CO;2-6

Demedts, I. K., Morel-Montero, A., Lebecque, S., Pacheco, Y., Cataldo, D., Joos, G. F., et al. (2006). Elevated MMP-12 protein levels in induced sputum from patients with COPD. Thorax 61, 196-201. doi: 10.1136/thx.2005.042432

Du, W., Hong, J., Wang, Y. C., Zhang, Y. J., Wang, P., Su, W. Y., et al. (2012). Inhibition of JAK2/STAT3 signalling induces colorectal cancer cell apoptosis via mitochondrial pathway. J. Cell. Mol. Med. 16, 1878-1888. doi: 10.1111/j.15824934.2011.01483. $\mathrm{x}$

El Kasmi, K. C., Holst, J., Coffre, M., Mielke, L., de Pauw, A., Lhocine, N., et al. (2006). General nature of the STAT3-activated antiinflammatory response. J. Immunol. 177, 7880-7888.

Foronjy, R., and D'Armiento, J. (2001). The role of collagenase in emphysema. Respir. Res. 2, 348-352. doi: 10.1186/rr85

Frobose, H., Ronn, S. G., Heding, P. E., Mendoza, H., Cohen, P., MandrupPoulsen, T., et al. (2006). Suppressor of cytokine signaling-3 inhibits interleukin-1 signaling by targeting the TRAF-6/TAK1 complex. Mol.
Endocrinol. 20, 1587-1596. doi: 10.1210/me.2005-0301

Gao, H., and Ward, P. A. (2007). STAT3 and suppressor of cytokine signaling 3: potential targets in lung inflammatory responses. Expert Opin. Ther. Targets 11, 869-880. doi: 10.1517/14728222.11.7.869

Geraghty, P., Hardigan, A. A., Wallace, A. M., Mirochnitchenko, O., Thankachen, J., Arellanos, L., et al. (2013). The GPx1-PTP1B-PP2A axis: a key determinant of airway inflammation and alveolar destruction. Am. J. Respir. Cell Mol. Biol. doi: 10.1165/rcmb.2013-0026OC. [Epub ahead of print].

Gerhartz, C., Heesel, B., Sasse, J., Hemmann, U., Landgraf, C., Schneider-Mergener, J., et al. (1996). Differential activation of acute phase response factor/STAT3 and STAT1 via the cytoplasmic domain of the interleukin 6 signal transducer gp130. I. Definition of a novel phosphotyrosine motif mediating STAT1 activation. J. Biol. Chem. 271, 12991-12998. doi: 10.1074/jbc.271.22.12999

Gobburu, J. V., Tenhoor, C., Rogge, M. C., Frazier, D. E. Jr., Thomas, D., Benjamin, C. et al. (1998). Pharmacokinetics/dynamics of $5 \mathrm{c} 8$, a monoclonal antibody to CD154 (CD40 ligand) suppression of an immune response in monkeys. J. Pharmacol. Exp. Ther. 286, 925-930.

Hautamaki, R. D., Kobayashi, D. K., Senior, R. M., and Shapiro, S. D. (1997). Requirement for macrophage elastase for cigarette smoke-induced emphysema in mice. Science 277, 2002-2004. doi: 10.1126/science.277.5334.2002

Ilumets, H., Rytila, P., Demedts, I., Brusselle, G. G., Sovijarvi, A., Myllarniemi, M., et al. (2007). Matrix metalloproteinases -8, -9 and -12 in smokers and patients with stage 0 COPD. Int. J. Chron. Obstruct. Pulmon. Dis. 2, 369-379.

Kim, V., and Criner, G. J. (2013). Chronic bronchitis and chronic obstructive pulmonary disease. Am. J. Respir. Crit. Care Med. 187, 228-237. doi: $10.1164 / \mathrm{rccm}$. 201210-1843CI

Koller, F. L., Dozier, E. A., Nam, K. T., Swee, M., Birkland, T. P., Parks, W. C., et al. (2012). Lack of MMP10 exacerbates experimental colitis and promotes development of inflammation-associated colonic dysplasia. Lab. Invest. 92, 1749-1759. doi: 10.1038/labinvest. 2012.141

Li, H., Huang, C., Huang, K., Wu, W., Jiang, T., Cao, J., et al. (2011). STAT3 knockdown reduces pancreatic cancer cell invasiveness and matrix metalloproteinase-7 expression in nude mice. PLoS ONE 6:e25941. doi: 10.1371/journal.pone.0025941

Macnee, W. (2007). Pathogenesis of chronic obstructive pulmonary disease. Clin. Chest Med. 28, 479-513. doi: 10.1016/j.ccm.2007.06.008

Matsukawa, A., Kudo, S., Maeda, T. Numata, K., Watanabe, H., Takeda, K., et al. (2005). Stat3 in resident macrophages as a repressor protein of inflammatory response. J. Immunol. 175, 3354-3359.

Mays, L. E., Ammon-Treiber, S., Mothes, B., Alkhaled, M., Rottenberger, J., Muller-Hermelink, E. S., et al. (2013). Modified Foxp3 mRNA protects against asthma through an IL-10-dependent mechanism. J. Clin. Invest. 123, 1216-1228. doi: 10.1172/JCI65351

Mercer, B., Kolesnikova, N. Sonett, J., and D'Armiento, J. (2004). Extracellular regulated kinase/mitogen activated protein kinase is up-regulated in pulmonary emphysema and mediates matrix metalloproteinase-1 induction by cigarette smoke. J. Biol. Chem. 279, 17690-17696. doi: 10.1074/jbc. M313842200

Miller, N., Simoes, E. J., Chang, J. C., and Robling, A. G. (2000). Trends in chronic obstructive pulmonary disease mortality. Mo. Med. 97, 87-90.

Monzon, M. E., Forteza, R. M., and Casalino-Matsuda, S. M. (2011). MCP-1/CCR2B-dependent loop upregulates MUC5AC and MUC5B in human airway epithelium. Am. J. Physiol. Lung Cell. Mol. Physiol. 300, L204-L215. doi: 10.1152/ajplung. 00292.2010

Murphy, B. S., Xu, J., and Kochanek, K. D. (2012). "Deaths: preliminary data for 2010," in National vital statistics reports, Vol. 60 . ed N. V. S. Reports (Hyattsville, MD: National Center for Health Statistics). Available online at: http://www.cdc.gov/nchs/data/nvsr/ nvsr60/nvsr60_04.pdf.

Pauwels, N. S., Bracke, K. R., Dupont, L. L., Van Pottelberge, G. R., Provoost, S., Vanden Berghe, T., et al. (2011). Role of IL-1alpha and the Nlrp3/caspase-1/IL-1beta axis in cigarette smoke-induced pulmonary inflammation and COPD. Eur. Respir. J. 38, 1019-1028. doi: 10.1183/09031936.00158110

Penttila, T., Haveri, A., Tammiruusu, A., Vuola, J. M., Lahesmaa, R., and Puolakkainen, M. (2008). Chlamydia pneumoniae infection in IL-10 knock out mice: accelerated clearance but severe pulmonary inflammatory response. Microb. Pathog. 45, 25-29. doi: 10.1016/j. micpath.2008.02.004

Puhr, M., Santer, F. R., Neuwirt, H., Marcias, G., Hobisch, A., and Culig, Z. (2010). SOCS-3 antagonises the proliferative and migratory effects of fibroblast growth factor-2 in prostate cancer by inhibition of p44/p42 MAPK signalling. Endocr. Relat. Cancer 17, 525-538. doi: 10.1677/ERC-10-0007

Qin, H., Holdbrooks, A. T., Liu, Y., Reynolds, S. L., Yanagisawa, L. L., and Benveniste, E. N. (2012a). SOCS3 deficiency promotes M1 macrophage polarization and inflammation. J. Immunol. 189 , 3439-3448. doi: 10.4049/jimmunol. 1201168

Qin, H., Yeh, W. I., De Sarno, P., Holdbrooks, A. T., Liu, Y., Muldowney, M. T., et al. (2012b). Signal transducer and activator of transcription3/suppressor of cytokine signaling-3 (STAT3/SOCS3) axis in myeloid cells regulates neuroinflammation. Proc. Natl. Acad. Sci. U.S.A. 109, 5004-5009. doi: 10.1073/pnas.1117 218109

Qu, P., Roberts, J., Li, Y., Albrecht, M., Cummings, O. W., Eble, J. N., et al. (2009). Stat3 downstream genes serve as biomarkers in human lung carcinomas and chronic obstructive pulmonary disease. Lung Cancer 63, 341-347. doi: 10.1016/j.lungcan. 2008.05.025

Raherison, C., and Girodet, P. O. (2009). Epidemiology of COPD Eur. Respir. Rev. 18, 213-221. doi: 10.1183/09059180.00003609

Riches, D. W., Chan, E. D., and Winston, B. W. (1996). TNF-alphainduced regulation and signalling in macrophages. Immunobiology 195, 477-490. doi: 10.1016/S0171-2985 (96)80017-9

Rodriguez, J. A., Orbe, J., Martinez de Lizarrondo, S., Calvayrac, O., Rodriguez, C., Martinez-Gonzalez, J., et al. (2008). Metalloproteinases and atherothrombosis: MMP-10 mediates vascular remodeling promoted by inflammatory stimuli. Front. Biosci. 13, 2916-2921. doi: 10.2741/2896

Ruan, M., Pederson, L., Bradley, E. W., Bamberger, A. M., and Oursler, M. J. (2010). Transforming growth factor-\{beta\} coordinately induces suppressor of cytokine signaling 3 and leukemia inhibitory factor to suppress osteoclast apoptosis. Endocrinology 151, 1713-1722. doi: 10.1210/en.2009-0813

Ruwanpura, S. M., McLeod, L., Miller, A., Jones, J., Vlahos, R., Ramm, 
G., et al. (2012). Deregulated Stat3 signaling dissociates pulmonary inflammation from emphysema in gp130 mutant mice. Am. J. Physiol. Lung Cell. Mol. Physiol. 302, L627-L639. doi: 10.1152/ajplung. 00285.2011

Saleh, A., Shan, L., Halayko, A. J., Kung, S., and Gounni, A. S. (2009). Critical role for STAT3 in IL17A-mediated CCL11 expression in human airway smooth muscle cells. J. Immunol. 182, 3357-3365. doi: 10.4049/jimmunol.0801882

Shapiro, S. D. (1999). The macrophage in chronic obstructive pulmonary disease. Am. J. Respir. Crit. Care Med. 160, S29-S32. doi: 10.1164/ajrccm.160.supplement_1.9

Shapiro, S. D. (2003). Proteolysis in the lung. Eur. Respir. J. Suppl. 44, 30S-32S. doi: 10.1183/09031936.03. 00000903a

Shapiro, S. D., Campbell, E. J., Senior, R. M., and Welgus, H. G. (1991). Proteinases secreted by human mononuclear phagocytes. J. Rheumatol. Suppl. 27, 95-98.

Simeone-Penney, M. C., Severgnini, M., Tu, P., Homer, R. J., Mariani, T. J., Cohn, L., et al. (2007). Airway epithelial STAT3 is required for allergic inflammation in a murine model of asthma. J. Immunol. 178, 6191-6199.

Smithgall, T. E., Briggs, S. D., Schreiner, S., Lerner, E. C., Cheng, H., and Wilson, M. B. (2000). Control of myeloid differentiation and survival by Stats. Oncogene 19, 2612-2618. doi: 10.1038/sj.onc. 1203477

Tuder, R. M., Zhen, L., Cho, C. Y., Taraseviciene-Stewart, L., Kasahara, Y., Salvemini, D., et al. (2003). Oxidative stress and apoptosis interact and cause emphysema due to vascular endothelial growth factor receptor blockade. Am. J. Resp. Cell Mol. Biol. 29, 88-97. doi: 10.1165/ rcmb.2002-0228OC

Williams, L., Bradley, L., Smith, A., and Foxwell, B. (2004). Signal transducer and activator of transcription 3 is the dominant mediator of the anti-inflammatory effects of IL-10 in human macrophages. J. Immunol. 172, 567-576.

Wright, J. L., Farmer, S. G., and Churg, A. (2002). Synthetic serine elastase inhibitor reduces cigarette smokeinduced emphysema in guinea pigs. Am. J. Respir. Crit. Care Med. 166, 954-960. doi: $10.1164 / \mathrm{rccm}$. 200202-098OC

Zhou, Z., Neupane, M., Zhou, H. R. Wu, D., Chang, C. C., MoustaidMoussa, N., et al. (2012). Leptin differentially regulate STAT3 activation in ob/ob mouse adipose mesenchymal stem cells. Nutr. Metab. (Lond.) 9, 109. doi: 10.1186/ 1743-7075-9-109

Conflict of Interest Statement: The authors declare that the research was conducted in the absence of any commercial or financial relationships that could be construed as a potential conflict of interest.
Received: 22 July 2013; accepted: 09 September 2013; published online: 01 October 2013.

Citation: Geraghty $P$, Wyman $A E$, Garcia-Arcos I, Dabo AJ, Gadhvi S and Foronjy $R$ (2013) STAT3 modulates cigarette smoke-induced inflammation and protease expression. Front. Physiol. 4:267. doi: 10.3389/fphys.2013.00267

This article was submitted to Respiratory Physiology, a section of the journal Frontiers in Physiology.

Copyright (c) 2013 Geraghty, Wyman, Garcia-Arcos, Dabo, Gadhvi and Foronjy. This is an open-access article distributed under the terms of the Creative Commons Attribution License (CC BY). The use, distribution or reproduction in other forums is permitted, provided the original author(s) or licensor are credited and that the original publication in this journal is cited, in accordance with accepted academic practice. No use, distribution or reproduction is permitted which does not comply with these terms. 